\title{
11 \\ Question Me an Answer: Re-awakening the Art of Inquiry in Post-Secondary Science Education
}

\author{
Anne Marie O’Beirne-Ryan \\ Dalhousie University
}

In our science learning and teaching environment, how often do we present science as a body offacts, or at best, a compendium of knowledge to which we can add more information, if we ask the "right" questions? In reality, the nature of science is significantly more complex, and the number of iterations we go through to resolve a given inquiry is often considerable. Similarly, how often do we vocalize the hope that our students will develop critical thinking, yet in reality, encourage only logical, linear thinking? Would science become more inclusive if we actually encouraged creative and divergent thinking in addition to logical-analytical thinking? Instead of "What?" can we ask "What if?" or even better, "What if not?" How might we begin to create learning environments where students themselves generate questions that facilitate deeper learning?

\section{Introduction}

Why is the sky blue? Why is the sea salty? Where does the sun go at night?

$\mathrm{T}$

hese are just a smattering of the questions you likely asked as a 3-year-old, and the point at which the inquiry base between us and our students began. Although, somewhere between the age of 3 and 18, many of these budding inquisitors have turned into passive producers at best, and they show up in our classes, willing to "learn," but not at all ready for our expectations of them as critical thinkers.

So how do we re-awaken this latent curiosity and interest in learning? And in particular, how do we re-kindle this kind of thirst for understanding and discovery that is so critical for science? Do we need to consider this at all? After all, is science not a body of facts, waiting to be recounted? No scientist would claim the latter, nor indeed would a scholar in any discipline refute the merit of questioning.

Why then do we so often, albeit unwittingly, present science to students, particularly in early undergraduate years, as a body of facts to be memorized and regurgitated? Without doubt, students do need 
to build on previous developments and understandings in their disciplines, and they certainly need to learn the language and fundamental concepts of the discipline, so that not only a common discourse, but also a shared meaning is possible. However, unless this learning of the language and common underpinnings of the discipline does not also result in students being brought more completely into the culture of the discipline and the joy of inquiry, their education is not complete - nor is their real understanding of science as a mode of inquiry.

\section{Nature or Science and Inquiry: Kuhn's Perspective}

Kuhn's perspective on the nature of science (1962) holds that scientific disciplines work under a given paradigm, or way of thinking, over a period of time. During the lifetime of a given paradigm, scientists proceed with what Kuhn refers to as "normal" science - where we work to confirm that our findings fit the existing paradigm. In other words, we develop questions, which we then seek to answer under the umbrella of the accepted paradigm. Revolutions in science require a paradigm shift, and these also evolve because scientists question what does not fit the current paradigm, why things cannot be explained, what might happen if..., and by pushing the boundaries of current scientific thought. During all stages within the nature of science as Kuhn describes it, inquiry is the key to the process. So, if science progresses through asking questions and then seeking answers to these questions, why do we persist in portraying science to students primarily as a body of already-accepted knowledge? True, our students are novices, but they are not novice encyclopedias; they are novice scientists.

\section{Habits-to-go and Aspirations}

Our teaching habits in science and beyond may read like this: we lecture, often for 50 minutes straight; we often test for factual recall; we give "dull," irrelevant assignments; and we do not share with our students our own scientific habits - that is, we do not "take off the tops of our heads" and show our students how we go about doing our science. In spite of this, if asked, we likely indicate that we would like our students to show a love of learning and engagement with the material. Yet, when we lecture and they passively listen, how can they actively engage? We might add that we wish students to develop critical thinking, yet we commonly present our discipline as simply a body of facts, so where is the room for them to become critical thinkers - critical...maybe! We certainly will claim that we expect our students to become effective problem-solvers, yet we seldom give them real, meaningful problems to consider. How can they really understand, when we neither model questioning nor encourage them to ask questions themselves, or indeed, even consider questioning their readings, notes, or our lectures? In other words, how can they take a deep approach to learning science (Entwistle, 1981) when we only require factual answers, encouraging a surface approach to learning, where students can succeed in the course by memorizing facts and neglecting connections between facts and processes (Ramsden, 1992)? van Zee, Iwasyk, Kurose, Simpson, and Wild (2001) assert that in an environment of respect, where students feel comfortable asking questions, and when invited to do so, do indeed ask questions. We cannot force student questions, but we can contribute to a supportive environment where questioning is accepted and encouraged.

So, what can we do to improve a student's quest in science? How do we reawaken the latent inquisitor? What follows is a number of ways in which I have attempted to re-awaken the thirst for discovery and meaning from a scientific perspective. This is not at all intended as an exhaustive compilation of ideas, but rather a starting point from which to springboard.

\section{Re-awakening Questioning}

\section{Modeling questioning behaviour}

In an undergraduate science class, when we present material to students solely through an uninterrupted lecture, what message are we conveying about science 
today? Some may argue that a lecture is the only way to cover the content. We ourselves like to listen to a good lecture (Think of the last lecture you attended. What proportion of the material presented do you actually remember?). Others may suggest that we "know" more than the students, and it is our duty to pass on the vast amount of amassed knowledge in our discipline. After all, students need all of this to be better prepared for the next course, grad school, work, etc. Still, others in the profession, especially those teaching at the first-year level, would contend that class size is too large to even think about teaching in any other way. However, numerous studies suggest that learning happens in an environment where active engagement rather than passive "participation" is the norm (Entwistle, 1981; Fink, 2003; van Zee et al., 2001).

Does this then mean that we should discard the lecture altogether? Not at all - we simply need to keep in mind that 20 minutes is a "good" attention span; students do not "learn" by simply listening and writing down everything we say; and asking, "Any questions...?" in the last couple of minutes of class, is not the best way to achieve engagement and inquiry on the part of students.

More than our words or their readings, students can learn from our behaviour. For this reason, perhaps one of the most important avenues to questioning that we can share with our students is if we too, are questioners, and we make this explicit in our teaching. One key way in which we might do this is to incorporate more inquiry into lectures, and we can do this even in large class settings. In addition to asking students to clarify or classify something during our lecture session, we can also consider such forms of questions as: "What if," or "Consider X by looking from a new perspective - what might happen then?" We might consider introducing what van Zee and Minstrell (1997) refer to as the "reflective toss" question, in which a student statement or response is followed by the instructor asking a reflective question. This reflective question encourages students collectively as well as individually, to elaborate on the idea, and in so doing, to take more responsibility for their thinking. Our lectures become enhanced when we ask questions throughout and encourage student questions, both in relation to what we are presenting, and also in response to the questions we pose. When we do this we not only model questioning skills, we also encourage students to stop, think, and re-activate their inquisitiveness. Indeed, as positive side effects, we break up the class as a whole, which serves to refocus attention and also allows us to clear up misconceptions and confusions before they become entrenched.

Thinking out loud when a student asks a question, asking ourselves how we might solve a problem, discussing how we go about solving a problem, and talking to students about "good" questions and how to use questions to think, are additional key ways in which we can contribute to helping students in the lecture room develop the type of inquiry we expect of them as novice scientists. As with the previous suggestions, these interactions can be accomplished in large classes just as effectively as in small class settings. In addition, when we ask questions in class, we should regularly remind students that they too should be asking themselves similar questions when they study. When we make the process of inquiry explicit to our students, we both speed up and deepen their mastery of the process of inquiry.

\section{Presenting a challenge or introducing incongruity}

Beginning a class with a problem, dilemma, or "trick" question related to the material at hand, is always a good way to capture the imagination and thinking process of students, particularly if much discussion is generated. For three to five minutes at the beginning of class, students can exchange ideas and possibilities related to the dilemma of the day and as before, this activity is not restricted to small classes. I have often followed this class exchange of ideas with a vote on "who thinks what." Depending on the nature of the dilemma, noting the diversity of ideas is often sufficient to help students think of more than one way to find an answer, or alternatively, if the dilemma does have a "better" answer, then this helps focus the discussion on why a particular response might be "better."

While in the middle of material on a given 
topic, the introduction of an apparent incongruity or anomaly is always a source of questioning and speculation. Constructivist theories on learning tell us that we create new knowledge based on prior knowledge (Mayer, 1996). When new material cannot be explained in terms of our prior knowledge, we can ignore it. If, on the other hand, the new anomalous information is not so far removed from our current schema, we may modify our schema in order to understand (Piaget, 1983; Kastens \& Ishiwaka, 2006). If we present puzzling ideas or information that is not too remote from their recent learning, students can experience a temporary discordance, and may subsequently respond by changing their preconceived notions.

\section{Using images to encourage questioning}

In many disciplines, using images provides another avenue for students to access information and understanding. Images form an additional means of communication and are particularly valuable for visual learners. Instead of always presenting the image with an explanation, we can ask students questions about the image, and again, this interaction can take place in a large class setting as readily as in a smaller class. Alternatively, we can ask students to develop a set of questions about an image. This is particularly useful if we use images to introduce a topic, or images that are unusual and require some thought. In the past, when I have asked students to generate questions based on an image, I have asked them to also divide their questions into ones they might classify as "factual" and ones they might consider "more than simply factual." Interestingly, this has raised a further sticking point with students; many students have difficulty determining what might be considered a "factual" question versus what might be a "more than factual" question. In other words, students really do not have a clear sense of the nature of questioning, what it is we might be questioning, the language around questioning, and how critical effective questioning really is; we must be their guides as they work through their broadening sense of inquiry.

\section{Timing and sensitivity in questioning}

If our questions are high stake, then only the most confident student will consider venturing a response. Questions with only one correct answer and those that have a mark attached to them are examples of what we might call "high stake" questions, and typically close down student inquiry. Similarly, questions asked early in the term may need more sensitive treatment. Early in the term, and when starting a new topic, I will often ask students how many of them have ever visited/seen/heard something related to the topic. As they respond with a show of hands, asking each student to briefly identify their experience has increased participation, opens up discussion, and allows me to draw on prior experiences. Similarly, beginning a topic with a question for which there is not simply one correct answer, such as "Given the following 3 choices, how many would chose 1, 2, and 3 respectively?" is another effective way to involve all students, and to start them thinking about the "why" of their choices. These two examples are "low stake" questions, and pose little or no threat to even the shyest student in a classroom, as they are the "expert" on their own experience and choices - and they can readily be asked to any number of students at a time.

\section{Is Questioning the Answer?}

Bloom (1956) developed a taxonomy of questioning, which at the lowest level involves recall of knowledge, and at a higher level, synthesis and evaluation, leading to deep learning. Although Bloom's taxonomy has stood the test of time, more recently, it has been modified to include questions that encourage creative and divergent thought (Anderson \& Krathwohl, 2001). We should ensure that our questions offer a balance of low level as well as higher level questions, and sometimes include questions that require students to think "outside the box," so students can move from surface to deep learning as they stretch toward understanding. If we turn the table and emphasize questioning of all kinds in addition to answering, what happens in our classrooms? Do we, in fact, create an environment where science is practiced from an early stage in a student's undergraduate years, and therefore, do we in the long term, potentially reap the benefit of a generation of scientists whose inquiry 
is rich and diverse? And indeed, in addition to elevating the base level of science for scientists, do we also help create a scientifically-literate society that knows how to question, rather than to accept as fact, all they read, hear, and see?

\section{References}

Anderson, L.W. \& Krathwohl, D.R. (Eds). (2001). A taxonomy for learning, teaching, and assessing: $A$ revision of Bloom's Taxonomy of educational objectives. New York: Longman.

Bloom, B.S. (1956). Taxonomy of educational objectives: The classification of educational goals. New York: Longman, Green.

Entwistle, N. (1981). Styles of learning and teaching: An integrated outline of educational psychology for students, teachers and lecturers. Chichester: John Wiley \& Sons.

Fink, L.D. (2003). Creating significant learning experiences. San Francisco: Jossey-Bass Publishing.

Kastens, K.A. \& Ishikawa,T. (2006). Spatial thinking in the geosciences and cognitive sciences: A cross-disciplinary look at the intersection of the two fields. Geological Society of America Special Paper 413, 53-76.

Kuhn, T.S. (1962). The structure of scientific revolutions. Chicago: University of Chicago Press.

Mayer, R. E. (1996). Learners as information processors: Legacies and limitations of educational psychology's second metaphor. Educational Psychologist, 31(3/4), 151-161.

Piaget, J. (1983). Piaget's theory. In W. Kessen (Ed.), Handbook of child psychology: History, theory, and methods ( $4^{\text {th }}$ ed., pp. 103-128). New York: Wiley.

Ramsden, P. (1992). Learning to teach in higher edu- cation. London: Routledge.

van Zee, E., Iwasyk, M., Kurose, A., Simpson, D., \& Wild, J. (2001). Student and teacher questioning during conversations about science. Journal of Research in Science Teaching, 38(2), 159-190.

van Zee, E. \& Minstrell, J. (1997). Using questioning to guide student thinking. The Journal of the Learning Sciences, 6(2), 227-269. 